\title{
Preliminary Thinking of China's Rural Culture Exploration and Mining: Based on User Experience
}

\author{
Ying Ge${ }^{1 *}$, Wei Zhang1,2, Mingfu Yao ${ }^{3}$, Yuanyan $\mathrm{Hu}^{1}$, Huamin $\mathrm{He}^{1}$ \\ ${ }^{1}$ User Experience and Human-Computer Interaction Technology Institute, Chongqing University of Arts and Sciences, \\ Chongqing, China \\ ${ }^{2}$ Chongqing Better Industrial Design Co., Ltd., Chongqing, China \\ ${ }^{3}$ The United Front Work Department of the CPC Xiaojin County Committee, Aba Tibetan and Qiang Autonomous Prefecture, \\ China \\ Email: *gy8620@163.com
}

How to cite this paper: Ge, Y., Zhang, W., Yao, M. F., Hu, Y. Y., \& He, H. M. (2021). Preliminary Thinking of China's Rural Culture Exploration and Mining: Based on User Experience. Chinese Studies, 10, 175-181. https://doi.org/10.4236/chnstd.2021.103011

Received: July 26, 2021

Accepted: August 20, 2021

Published: August 23, 2021

Copyright (c) 2021 by author(s) and Scientific Research Publishing Inc. This work is licensed under the Creative Commons Attribution International License (CC BY 4.0).

http://creativecommons.org/licenses/by/4.0/

\begin{abstract}
As a national development strategy, rural revitalization is of great significance in China's modern construction, among which cultural revitalization plays a leading role. This paper will discuss the way to explore rural culture from the perspective of user experience. With a focus on such fields as "eating, clothing, housing, travel, and recreation" that are familiar to the general public, it aims to highlight the protection, inheritance, and development of rural culture, and talent training, and promote rural cultural landscapes and immersive experience of farming culture, as well as cultural productization and the extension of cultural connotation to properly satisfy users' diversified needs and facilitate the national rural revitalization.
\end{abstract}

\section{Keywords}

China's Rural Revitalization, Rural Culture Exploration and Mining, User Experience

\section{Introduction}

On October 18, 2017, Chinese President Xi Jin-ping proposed the rural revitalization strategy in the Report on the 19th National Congress of the Communist Party of China (CPC). Thereafter, all regions and organizations have worked around issues relating to "agriculture, rural areas, and rural people". At the Fifth Plenary Session of the 19th CPC Central Committee in late October 2020, China 
stated to "prioritize the development of agriculture and rural areas and fully advance rural vitalization", which further explains the rural revitalization strategy in the Report and loyally follows the requirements to further promote the "14th Five-Year Plan" and the "Long-Range Objectives Through the Year 2035".

Rural revitalization will be implemented from five aspects, namely industry, talent, culture, ecology, and organization. Among them, cultural revitalization plays a leading role (CPC Central Committee, State Council, 2018). Rural culture is a new culture attributable to the organic integration of excellent traditional Chinese culture and core socialist values, reflecting profound cultural traditions and rich contemporary characteristics. Rural cultural revitalization, in essence, is to protect, inherit, explore, and develop fine local culture, cultivate outstanding local rural culture talent, comprehensively study cultural tolerance and community user experience, and eventually create an integral and excellent environment for rural cultural revitalization.

Now, China is speeding up efforts to foster a new development paradigm with domestic circulation as the mainstay and domestic and international circulations reinforcing each other. In the context of domestic circulation, rural revitalization plays an important role in the development plan of telling China's stories well. Rural cultural industries are able to promote domestic circulation. A variety of rural cultural industries and products are taking part into the national economy and people's livelihood to enrich people's needs for diversified consumption and create various conditions for rural people's wealth accumulation.

\section{Connection between User Experience and Rural Cultural Revitalization}

According to the ISO9241-210: Ergonomics of Human-System Interaction, user experience is "a person's perceptions and responses that result from the use of a product, system, or service, including all the user's emotions, beliefs, preferences, perceptions, physical and psychological responses, behaviors, and accomplishments that occur before, during, and after use." In 2019, six authorities including the Ministry of Science and Technology of the People's Republic of China issued the Guidance on Promoting Deep Integration of Culture and Technology, stressing to "promote the better and faster development of cultural programs and industries, better meet the intellectual and cultural needs of the people, and enhance the people's sense of contentment and happiness", revealing the supporting role of "user experience" in advancing the supply-side reform, the strategy for improving China's strength in product quality, and other national strategies and actions.

Traditionally, the subject of rural cultural revitalization refers to local farmers and a portion of migrant entrepreneurs. At present, the cultivation of the subject mainly focuses on creating a good entrepreneurial environment for those who come back and migrate to the place, but cultural bearers or users are often neglected. Whether all products and services are suitable and effective is eventually 
determined by end users (Ge \& Xu, 2020). Therefore, "users" should be also a main part of the subject. It should be more targeted to explore rural cultural revitalization from the aspect of user experience.

For a long time, agriculture had dominated Chinese society, contributing to the long history of rural culture. Rural culture refers to both tangible cultural forms such as rural buildings, rural landscapes, and production tools and intangible forms like rural conventions, folk customs, intangible cultural heritage items, and local practices (Zhang, 2018). Currently, certain results have been achieved in the protection and inheritance of tangible cultural forms. However, more efforts should be made to exploit and explore intangible cultural forms, especially some typical and fragmented local cultural elements.

Culture is rooted in the life and serves life. Better cultural inheritance and development must be in response to the people's needs for a better life, so the user experience-oriented exploration of rural culture-which is also for the purpose of development - can be a driving force of rural cultural revitalization. In general, "passive exploration" is a research pattern that researchers discover and study something after its appearance. However, the user experience-oriented pattern is active and divergent. Under this pattern, researchers actively discover items that may be left out by studying cultural carriers like local folk customs. Cultural exploration finally serves the application. Precisely speaking, it will be used to create cultural and creative products based on user experience. For example, cultural and creative products created by the Palace Museum of China have mixed the market demands and cultural inheritance, pushing the museum to explore and develop its existing culture and resources.

Common industries and products derived from rural culture include some cultural tourism products, such as agritainment, picking-up festivals, fruiter adoption, organic agricultural product experience, and natural scenery and agricultural sightseeing. Some are cultural and creative products, such as life products, new local operas, and lantern festivals with modern technological elements. These industries and products can effectively promote the agricultural supply-side development and satisfy the people's diversified needs for life. While accepted by the market and creating economic and social values, they can nurture the exploration and mining of rural culture to form a benign interaction on the whole industry chain, thus promoting rural cultural revitalization in the end.

\section{User Experience-Based Exploration and Mining of Rural Culture}

User experience-based exploration of rural culture highlights cultural transformation, moderate cultural creation, and cultural tourism development based on user experience, in the hope of popularizing fine rural culture and rural areas and helping creative protection and inheritance of local culture.

1) Objects and Domains for Exploration and Mining of Rural Culture

Currently, the exploration and mining of rural culture focuses on familiar 
areas, namely "eating, clothing, housing, travel, and recreation", showing all dimensions of rural people's daily life.

"Eating"

Eating is crucial to survival and rural prosperity. Everything in life or production centers on "eating". Study on "eating" also reveals many other things, such as means of production and functions of production tools, which are reflected in the development and utilization of ingredients, the use and innovation of tableware, food processing, dining etiquette and customs, and dining-related culture (Luo \& Chen, 2020). The people's life experience needs will evolve with productivity improvement. Both rural people and non-locals can enjoy these services, demonstrating the original rural user experience improvement act.

"Clothing"

Clothing, a living demand, is a product of productivity improvement and social civilization development. In ancient times, fur and leaves can meet the basic needs for warmth. However, in modern times, "clothing" has multiple meanings. There are various dress styles to meet the people's experience needs of "dressing self” (Xu, 2020). China is rich in clothing culture and technology. In particular, the clothing culture of minorities is gorgeous and brilliant (Bi, 2020). Clothing is a product unique to humans, which is loaded with lifestyle and customs, aesthetic taste, color preference, cultural mindsets, and religious ideas. While exploring rural culture, we can probe into the cultural nature behind rural dressing styles by studying "clothing".

\section{"Housing"}

Housing essentially reflects the improvement of the people's survival experience and life quality. In the beginning, people lived in "caves" for self-protection. Gradually, the "living" conditions have been improved with different functions and humans have also enhanced aesthetic quality. Residences display owners' living conditions and reveal the family ties and the social relations with the neighbors. China's rural dwellings in different styles are an important carrier of cultural transmission (Zhang \& Zhang, 2020). From cottages and brick houses to small western-style buildings and small quadrangle dwellings in new rural areas, all demonstrate rural people's true experience needs (Sun, 2020). Studies on rural dwellings can demonstrate the changes in carriers of rural culture and its inheritance.

"Travel"

Travel is a need for survival and social communication. Throughout history, travel provides more survival possibilities for people. Evolution of means of transportation has reflected the improvement of productivity, social class, and social civilization. Studies on "travel" can reveal the local culture and discover the paths and signs of cultural transmission, integration, and development (Xu \& Wu, 2020). The development of "travel" history has been reflected in the evolution of rural culture.

\section{"Recreation"}

Recreation reflects people's spiritual life experience and emotional appeal, and 
recreational activities are social behaviors taken by people to enrich their lives. In the rural environment, folk songs and music, local operas, and others are the common recreational ways in the fields and cottages. Popular rural recreational activities not only mirror people's consumption patterns in the spiritual sense in addition to production and labor activities, but also show the mental outlook and unique customs of the local people (Ye, 2020). Through the study into recreational activities, we can discover the manifestation pattern of the local rural culture and the origin of the rural culture more directly.

\section{2) Methods and Forms of Exploration and Mining of Rural Culture}

The methods and forms of exploration of rural culture oriented by user experience are as follows: a) Visiting natural villages to record oral cultures. The oral culture history of the interviewees is recorded with a focus on the above-mentioned aspects of "eating, clothing, housing, travel, and recreation". By taking photos, videotaping, copying, and other technical means, the existing cultural phenomena in the local villages are recorded. b) By visiting local museums, cultural centers, ancestral halls, and other places with obvious cultural elements and symbols, the elements in relation to some fragments before are found, which are linked to the cultural phenomena that have been explored or not fully explored before to conduct association study and form a chain of cultural elements. c) Establishing a return visit and liaison mechanism. The establishment of a return visit and liaison mechanism can effectively help trail the previous cultural exploration while timely grasping the current situation of local cultural protection and development, thus providing information support for the follow-up rural cultural exploration work. d) Training local talent to build a team for exploration of rural culture. Cultivating local talent lays a good foundation of talent resources for the development of local rural cultural undertakings. e) Fostering user groups for the utilization and sharing of rural culture. By grasping the psychological needs and characteristics of contemporary people, the essence of traditional brilliant rural culture is reinterpreted and conveyed in a modern discourse system, thus for increasing the sense of identity and promoting the continuous formation of new user groups.

\section{3) Rural Culture Transformation and Application}

Development-oriented rural culture exploration requires the development and transformation of cultural products and industries.

\section{Visualization and landscaping of rural ecology and cultural customs}

Rural ecology and cultural customs are the epitome of rural history and culture, representing the character of the countryside. In a landscape way, rural culture is materialized into a series of unique and more visible cultural symbols, which can be quickly perceived by people and provide them with great aesthetic pleasure. With buildings, landscape walls, screen walls, landscaping decorations, decorative veneers, bounding walls, squares, stools, and roads as carriers, the rural cultural landscape is formed through borrowing, transposition, superposition, material use, reduction, illusion, and other ways; with "Picking-up Festiv- 
al", "Harvest Festival", "Temple Fair", and others as the media, the spread and transformation of rural natural ecology and cultural customs are visualized (Li, 2019).

Immersive participation of farming culture and agricultural experience tourism

Farming display reflects the formation and development history of agriculture. Through on-site and online displaying forms, agricultural products, their producing areas, and the relevant farming culture are disseminated. The tourism mining in relation to farming culture and agricultural planting experience and harvest focuses on the experience demands of users and the presentation of product quality. The key to agricultural experience tourism is to take the local unique rural and agricultural tourism products or brilliant agricultural cultures that are worth carrying forward as the support and base itself on the highlights of excellent rural cultural resources to create scenes in a situational and storytelling way, in order to make tourists feel immersed and resonate with what is exhibited emotionally (Li \& Yang, 2021).

\section{Productization of rural cultures and extension of cultural connotation}

In the process of cultural transmission and experience, the customs that user groups are interested in are refined for the development of cultural and creative products, and the local unique cultural elements are redesigned to create household supplies, equipment, tools, and others that users like and are willing to use for their desirable design, good quality, profound connotations, and creative packaging. In addition to integrating rural culture into product design, the material, spiritual, and aesthetic needs of urbanites should be met (He, 2021).

\section{Conflicts of Interest}

The authors declare no conflicts of interest regarding the publication of this paper.

\section{References}

Bi, D. N. (2020). Language of the National Character of the Lahu Nationality's Costumes. Jiangsu Textile, No. 2, 96-97.

CPC Central Committee, The State Council of the People's Republic of China. (2018, September 26). Strategy Plan for Rural Vitalization (2018-2022). http://www.gov.cn/zhengce/2018-09/26/content 5325534.htm

Ge, L. Z., \& Xu, W. (2020). User Experience: Theory and Practice. China Renmin University Press.

He, D. P. (2021). Analysis on the Main Points of Rural Tourism Design from the Perspective of Rural Revitalization Strategy. Finance and Management, 4, 45-47.

Li, J., \& Yang, S. (2021). Integration of Rural Revitalization and Ecological Civilization: Logic, Value, and Path. Research on Governance Modernization, 37, 90-96.

Li, X. J. (2019). Study on Rural Tourism Strategy from the Perspective of Rural Revitalization Strategy. Consume Guide, No. 21, 58-59.

Luo, Z. Q., \& Chen, Q. (2020). Research on the Development of Rural Food Culture 
Tourism Resources under the Background of Rural Revitalization. Rural Science and Technology, No. 13, 33, 35.

Sun, L. (2020). Fengxian Develops Characteristic B\&B to Facilitate Rural Revitalization. Shanghai Rural Economy, No. 3, 12-14.

$\mathrm{Xu}, \mathrm{W}$. (2020). Study on the Inheritance and Development of Chinese Costume Culture. Fine Arts Literature, 165, 38-40.

Xu, X., \& Wu, Q. Q. (2020). Study on the Path of Transportation Infrastructure Allocation in Rural Revitalization Strategy. Journal of Chang'an University Social Science Edition, No. 4, 41-50.

Ye, Z. Y. (2020). Study on the Development of Rural Tourism in Minority Areas-A Case Study of Rural Tourism in Yi Nationality Area of Mengzi. Culture Industry, 175, 12-13.

Zhang, J. (2018). Rural Value Positioning and Rural Revitalization. Chinese Rural Economy, No. 1, 2-10.

Zhang, L. L., \& Zhang, L. Z. (2020). Study on Inheritance and Innovation of Landscapes of Ancient Residences in Wuling Mountain Area from the Perspective of Rural Revitalization Strategy. Housing Real Estate, No. 12, 252, 255. 